\title{
Nutritional management of enterocutaneous fistula: a retrospective study at a Malaysian university medical center
}

This article was published in the following Dove Press journal:

Journal of Multidisciplinary Healthcare

20 August 2014

Number of times this article has been viewed

\author{
Manal MH Badrasawi' \\ Suzana Shahar' \\ Ismail Sagap ${ }^{2}$ \\ 'Dietetics Program, School of \\ Health Care Sciences, Faculty \\ of Health Sciences, ${ }^{2}$ Department \\ of Surgery, Faculty of Medicine, \\ UKM Medical Center, Universiti \\ Kebangsaan Malaysia, Kuala Lumpur, \\ Malaysia
}

\begin{abstract}
Enterocutaneous fistula is a challenging clinical condition with serious complications and considerable morbidity and mortality. Early nutritional support has been found to decrease these complications and to improve the clinical outcome. Location of the fistula and physiological status affect the nutrition management plan in terms of feeding route, calories, and protein requirements. This study investigated the nutritional management procedures at the Universiti Kebangsaan Malaysia Medical Center, and attempted to determine factors that affect the clinical outcome. Nutritional management was evaluated retrospectively in 22 patients with enterocutaneous fistula seen over a 5-year period. Medical records were reviewed to obtain data on nutritional status, biochemical indices, and route and tolerance of feeding. Calories and protein requirements are reported and categorized. The results show that surgery was the predominant etiology and low output fistula was the major physiological category; anatomically, the majority were ileocutaneous. The spontaneous healing rate was $14 \%$, the total healing rate was $45 \%$, and the mortality rate was $22 \%$, with $14 \%$ due to fistula-associated complications. There was a significant relationship between body mass index/serum albumin levels and fistula healing; these parameters also had a significant relationship with mortality. Glutamine was used in 50\% of cases; however, there was no significant relationship with fistula healing or mortality rate. The nutritional status of the patient has an important impact on the clinical outcome. Conservative management that includes nutrition support is very important in order to improve nutritional status before surgical repair of the fistula.
\end{abstract}

Keywords: enterocutaneous fistula, nutritional management, retrospective study

\section{Background}

Management of enterocutaneous fistula is a challenge for surgeons, gastroenterologists, and allied health professionals ${ }^{1-4}$ because of the serious complications that can occur, ie, malnutrition, sepsis, and fluid and electrolyte disturbances, ${ }^{5}$ known as the "fistula triad". ${ }^{6}$ The main goal in management of enterocutaneous fistula is to restore the integrity of the patient's gastrointestinal tract to allow normal feeding while minimizing morbidity and mortality. ${ }^{3}$ The management plan is usually divided into three phases. The first phase, ie, recognition and stabilization, includes resuscitation of the patient, control of sepsis, electrolyte repletion, control of fistula drainage, and supply of nutrition. In the second phase, a fistulogram is performed to identify the anatomy and characteristics of the fistula. In the third phase, a decision is taken regarding the duration of conservative management and the operative plan based on an evaluation of the patient and the fistula. ${ }^{7}$

Nutritional support involves assessment, diagnosis, ordering, preparation, distribution, administration, and monitoring of nutrition. It includes total parenteral
Correspondence: Suzana Shahar Dietetics Programme Centre of Health Care Sciences, Faculty of Health Sciences, Universiti Kebangsaan Malaysia, Jalam Raja Muda Abd Aziz, Kampong Baru, Kuala Lumpur 53100, Malaysia

Email suzana.shahar@gmail.com 
nutrition (TPN), enteral feeding, or oral feeding, and plays a major role in management of enterocutaneous fistula..$^{8-10}$ It begins with calculating calories and protein requirements, assessing tolerance of the feeding regimen, modifying feeding methods, adjusting nutritional requirements according to changes in clinical status, and finally, observing for feeding complications. ${ }^{11}$ Classification of the fistula affects the route of feeding and caloric and protein requirements, ${ }^{12} \mathrm{ie}$, patients with high output fistula should receive more calories and protein than those with low output fistula who mostly require TPN. Oral and enteral feeding increase the fistula output if the fistula occurs in the proximal part of the gut. ${ }^{2}$ Therefore, a multidisciplinary team should be involved in designing and performing the management plan. ${ }^{13}$ Despite attention to nutritional support, malnutrition remains a major clinical problem in 50\%-90\% of patients with enterocutaneous fistula. ${ }^{2}$ Earlier researchers have noted that there are no experimental data for optimal routes of feeding in patients with enterocutaneous fistula, ${ }^{14}$ and any relevant reports are based on observational studies.

This study reports on the nutritional management of patients with enterocutaneous fistula admitted to the National University of Malaysia Medical Center and factors affecting the outcome of treatment.

\section{Materials and methods}

This retrospective observational study identified 28 cases admitted to the National University of Malaysia Medical Center between 2007 and 2012 based on manual screening of the census books held in the general surgery ward. Twentysix files available at the medical records unit were reviewed to extract the relevant data. Four cases were excluded because of incomplete information regarding nutritional management or lack of basic anthropometric measurements.

The data extracted included a detailed medical history, clinical status, and anatomic, etiologic, and physiologic classification of fistula. Physiologic classification was done by calculating the mean fistula output for the first 3 days, starting from the day the fistula was first recognized, using the following output cutoff points: low $<200 \mathrm{~mL} /$ day; moderate 200-500 mL/day; and high $>500 \mathrm{~mL} /$ day. $^{2}$ Each patient's nutritional status on admission and discharge was assessed using the available data for weight, body mass index, subjective global assessment, and serum albumin level.

The nutritional management plan and monitoring were investigated for each case individually, and categorized according to the route of feeding, duration of feeding, caloric and protein requirements, and type of formula, ie, enteral or parenteral. Refeeding syndrome was deemed to have occurred if a team member recommended cessation or a decrease in feeding in the presence of hypokalemia, hyponatremia, and hypophosphatemia. ${ }^{15}$ The medical notes for nutritional management recorded by all health professionals, ie, surgeons, nurses, dieticians, clinical pharmacists, psychologists, and physiotherapists, were reviewed for all cases.

Enterocutaneous fistula-related complications, including sepsis, electrolyte disturbances, dehydration, and malnutrition documented in the medical notes were also recorded. Patients who had multiple admissions were considered as single cases. Nutritional management was planned individually, depending on the patient's general status, because guidelines for nutritional support in patients with enterocutaneous fistula were not available.

Fisher's exact test was used to determine relationships between categoric variables, ie, nutritional status classification, and mortality, spontaneous healing, or occurrence of complications. The relationship between nutrition parameters and fistula healing was determined using Spearman's correlation coefficient test. Further analysis using multiple linear regression was applied to determine the predictive variables. Cox regression analysis was performed to identify factors affecting mortality. Descriptive statistics were used for type of fistula, mortality, fistula healing, and clinical complication rates.

\section{Results}

Only 22 of the 28 cases with enterocutaneous fistula identified met our inclusion criteria. These included 16 males and six females of mean age $50 \pm 17$ (range 16-72) years. The majority of cases were Malay $(n=17)$, with a minority being Chinese $(n=5)$. Comorbidities included hypertension $(n=8)$, stage 4 chronic kidney disease $(n=2)$, diabetes $(n=2)$, hepatic disease $(n=1)$, and cerebrovascular accident $(n=1)$. A history or presence of malignancy was reported in ten cases. Single or multiple laparotomy had been performed before formation of the fistula in all but two cases. The mean duration of hospital stay was $27.4 \pm 16$ (range 8-65) days.

\section{Nutritional status}

Mean body mass index was $20.1 \pm 3.6(14.0-32.0) \mathrm{kg} / \mathrm{m}^{2}$. Five cases were underweight, eleven were normal weight, two were overweight, and four were obese. Subjective global assessment was reported for nine cases, seven of whom were severely malnourished and the other two were mildly to moderately malnourished. The mean albumin 
level on admission was $27.9 \pm 8.7$ (range 15-44) $\mathrm{mmol} / \mathrm{L}$ and at discharge (or the last reading before discharge) was $29.2 \pm 8.6(13-43) \mathrm{mmol} / \mathrm{L}$.

\section{Fistula classification and sequelae}

The main etiology of fistula was surgical (in 20 cases), and the remaining cases were spontaneous, with one case due to inflammatory bowel disease and the other being an iatrogenic fistula. Most of the cases involved single fistula, with only one case of multiple fistulae. Low output was the major physiologic classification ( 15 cases), followed by high output fistula in six cases and medium output in one case. With regard to anatomic classification, the majority ( 15 cases) were iliac fistulae, while six cases involved the colon and two cases involved the jejunum. There was only one case of duodenal fistula (see Table 1).

The mortality rate was $23 \%$ (five cases). Three deaths were due to complications, eg, sepsis. Spontaneous healing of the fistula was achieved in only three cases by conservative treatment alone, while seven cases required conservative management followed by surgical repair. Two cases were repaired surgically immediately after occurrence of the fistula. The overall healing rate with surgical repair and/or conservative management was $45 \%$.

Sepsis occurred in eleven cases, electrolyte disturbances occurred in eight, and dehydration in three. Three cases developed a combination of sepsis, electrolyte disturbance, and dehydration. Four cases developed sepsis and electrolyte disturbance. Elevated liver enzymes were reported in two cases during TPN, and five cases were admitted to the intensive care unit. Conservative management was the first choice for management in $76 \%$ of cases.

\section{Nutritional management regimen}

The medical records showed that the following parameters affected the nutritional management plan: fistula output, functional status of the gastrointestinal tract, location of fistula (proximal or distal), feeding tolerance, presence of complications such as sepsis, TPN (liver)-related complications, and need for patient to be nil per mouth before surgery.

Table I Summary of the cases according to selected variables

\begin{tabular}{|c|c|c|c|c|c|c|c|c|c|c|c|c|}
\hline Number & $\begin{array}{l}\text { Age, } \\
\text { years }\end{array}$ & Sex & $\begin{array}{l}\text { Anatomic } \\
\text { position }\end{array}$ & Etiology & Physiology & $\begin{array}{l}\text { Start } \\
\text { feeding* }\end{array}$ & $\begin{array}{l}\text { Days } \\
\text { of TPN }\end{array}$ & $\begin{array}{l}\text { Days } \\
\text { of EF }\end{array}$ & Oral & Healing & LOS & Mortality \\
\hline $\mathrm{I}$ & 46 & Male & Jejunum & Postoperative & LOP & 5 & - & 14 & - & Not & 19 & - \\
\hline 2 & 71 & Female & Jejunum & Postoperative & LOP & 6 & 12 & - & 3 & Not & 45 & - \\
\hline 3 & 67 & Female & Ileum & Postoperative & LOP & 5 & 3 & 14 & - & Not & 32 & - \\
\hline 4 & 57 & Female & Ileum & Postoperative & LOP & 4 & 3 & - & 9 & Healed & 15 & - \\
\hline 5 & 16 & Male & $\begin{array}{l}\text { Terminal } \\
\text { ileum }\end{array}$ & IBD & HOP & 7 & 25 & - & 5 & Healed & 38 & - \\
\hline 6 & 72 & Female & Duodenum & latrogenic & MOP & 6 & - & 9 & - & Not & 23 & + \\
\hline 7 & 72 & Male & Ileum & Postoperative & HOP & 7 & 8 & 20 & - & Not & 37 & + \\
\hline 8 & 61 & Male & Ileum & Postoperative & LOP & I & - & 14 & - & Not & 17 & - \\
\hline 9 & 32 & Male & Ileum & Postoperative & HOP & 6 & 9 & - & 5 & Not & 48 & + \\
\hline 10 & 41 & Male & Colon & Postoperative & LOP & 4 & - & 14 & - & Healed & 11 & - \\
\hline II & 27 & Male & Colon & Postoperative & LOP & 8 & 5 & - & - & Healed & 17 & - \\
\hline 12 & 40 & Male & $\begin{array}{l}\text { Ascending } \\
\text { colon }\end{array}$ & Postoperative & LOP & 7 & - & - & 4 & Not & 8 & - \\
\hline 13 & 52 & Male & Ileum & Postoperative & LOP & 6 & - & 9 & - & Healed & 8 & - \\
\hline 14 & 41 & Male & Ileum & Postoperative & LOP & 6 & - & 20 & 4 & Healed & 9 & - \\
\hline 15 & 41 & Male & Ileum & Postoperative & LOP & 7 & 14 & 14 & 11 & Not & 30 & - \\
\hline 16 & 53 & Male & Ileum & Postoperative & LOP & 3 & 23 & - & 4 & Healed & 45 & - \\
\hline 17 & 18 & Male & Ileum & Postoperative & LOP & 5 & 29 & - & 32 & Healed & 64 & + \\
\hline 18 & 57 & Female & $\begin{array}{l}\text { Descending } \\
\text { colon }\end{array}$ & Postoperative & LOP & 4 & - & - & 14 & Not & 17 & - \\
\hline 19 & 67 & Female & Ileum & Postoperative & LOP & 3 & 12 & - & 4 & Not & 18 & - \\
\hline 20 & 57 & Female & $\begin{array}{l}\text { Descending } \\
\text { colon }\end{array}$ & Postoperative & LOP & 4 & - & - & 14 & Not & 17 & - \\
\hline 21 & 53 & Male & Ileum & Postoperative & LOP & 3 & 23 & - & 4 & Healed & 45 & - \\
\hline 22 & 41 & Male & Colon & Postoperative & LOP & 4 & - & 14 & - & Healed & 11 & - \\
\hline
\end{tabular}

Notes: *From the day of admission; + mortality occurred and was reported; - mortality did not occur/was not reported.

Abbreviations: LOP, low output; MOP, medium output; HOP, high output; EF, enteral feeding; TPN, total parenteral nutrition; Oral, days of oral feeding using nutritional formula; IBD, inflammatory bowel disease; LOS, length of stay. 
The nutritional management regimens were as follows: TPN with enteral feeding followed by oral nutrition or sip feeding; TPN followed by oral feeding; enteral feeding followed by oral feeding; TPN only; enteral feeding only; and oral feeding only. The duration and route of nutritional management is summarized in Table 1.

Glutamine was given to nine cases, either by intravenous infusion, or by adding it to the TPN bag. Indications for oral glutamine included occurrence of or risk of sepsis (ie, uncontrolled effluent from the fistula). ${ }^{7}$ However, no significant relationship was found between fistula healing and mortality with intravenous glutamine.

Ready-mixed TPN bags were given to $14(50 \%)$ of the patients, while the rest were given compound TPN bags. Standard formulae were used in most patients, but a modular formula (myotein) was added to the standard formula in one case $(4.5 \%)$. Three cases (14\%) were temporally given elemental formula after converting from TPN to enteral feeding. Patient caloric and protein requirements were calculated using a rapid method. Calories were given as $20-35 \mathrm{kcal} / \mathrm{kg} /$ day and protein was given as $1.2-2 \mathrm{~g} / \mathrm{kg} /$ day.

The relationship between anatomic fistula classification and spontaneous healing was analyzed by Fisher's exact test, and the associations were not significant at $P$ - value $<0.05$. The relationship between days of nil per mouth and the final albumin result was not statistically significant $(P=0.77$, Pearson's correlation coefficient test; Table 2). No significant predictor was found for mortality using Cox regression analysis (Table 3).

The relationship between fistula healing and mortality as dependent variables and etiology of the fistula, physiological status, and patient nutritional status showed different levels of significance (Table 4). The relationship between nutritional management regimen with serum albumin level at discharge was not statistically significant, but the relationship was significant with the length of hospital stay $(P<0.05$, Kruskal-Wallis test).

Table 2 Correlation between fistula healing and nutritional parameters

\begin{tabular}{llllll}
\hline \multicolumn{5}{l}{ Nutritional parameters } \\
\cline { 2 - 6 } & BMI & $\begin{array}{l}\text { Albumin (on } \\
\text { admission) }\end{array}$ & $\begin{array}{l}\text { Total } \\
\text { protein (on } \\
\text { admission) }\end{array}$ & $\begin{array}{l}\text { Days of } \\
\text { NPO }\end{array}$ & $\begin{array}{l}\text { Days of } \\
\text { TPN }\end{array}$ \\
\hline $\begin{array}{l}\text { Fistula } \\
\text { healing } \\
P \text {-value* }\end{array}$ & 0.344 & 0.330 & 0.343 & -0.150 & 0.342 \\
\hline
\end{tabular}

Note: *Using Spearman's correlation test.

Abbreviations: BMI, body mass index; NPO, nil per mouth; TPN, total parenteral nutrition.
Table 3 Relationship between fistula healing, mortality, and nutritional parameters

\begin{tabular}{|c|c|c|c|c|}
\hline \multirow[t]{2}{*}{ Nutrition parameters } & \multirow[t]{2}{*}{$P$-value } & \multirow[t]{2}{*}{$\operatorname{Exp}(B)$} & \multicolumn{2}{|l|}{$95 \% \mathrm{Cl}$} \\
\hline & & & $\begin{array}{l}\text { Lower } \\
\text { bound }\end{array}$ & $\begin{array}{l}\text { Higher } \\
\text { bound }\end{array}$ \\
\hline \multicolumn{5}{|l|}{ Fistula healing ${ }^{a}$} \\
\hline BMI & 0.008 & 1.328 & 0.959 & 1.839 \\
\hline Albumin (upon admission) & 0.121 & 1.096 & 0.976 & 1.23 \\
\hline Days of NPO & 0.484 & 0.809 & 0.447 & 1.46 \\
\hline Days of TPN & 0.117 & 1.127 & 0.97 & 1.30 \\
\hline Use of glutamine & 0.645 & 1.07 & 0.19 & 5.91 \\
\hline \multicolumn{5}{|l|}{ Mortality ${ }^{\mathrm{b}}$} \\
\hline BMI & 0.343 & 0.847 & 0.60 & $\mathrm{I} .194$ \\
\hline Albumin (upon admission) & 0.412 & 0.919 & 0.752 & 1.12 \\
\hline Days of NPO & 0.264 & 2.934 & 0.443 & 10.42 \\
\hline Days of TPN & 0.606 & 0.822 & 0.822 & 1.12 \\
\hline Use of glutamine & 0.200 & 5.197 & 0.418 & 64.5 \\
\hline
\end{tabular}

Notes: aLogistic regression test; ${ }^{\circ}$ Cox regression test.

Abbreviations: BMl, body mass index; $\mathrm{Cl}$, confidence interval; NPO, nil per mouth; TPN, total parenteral nutrition; Exp (B), exponential B (odds ratio).

\section{Discussion}

The results of this study show that the most common etiology of fistula was surgery and sepsis was the main reason for the considerable mortality rate. Fistula healing was significantly related to certain aspects of nutritional status. There was no significant difference in nutritional status according to the nutrition support regimen used, but there was a significant difference according to period of hospitalization. The spontaneous healing rate after conservative management was $14 \%$, and the total healing rate was $45 \%$. Spontaneous healing was associated with low output, a surgical etiology, and absence of sepsis. Several factors have already been reported to affect the rate of spontaneous healing, including surgical etiology and low output, with no associated abscess or comorbidity. ${ }^{14}$ However, a few studies have shown a higher fistula healing rate. ${ }^{16-18}$ The highest healing rate of $81 \%$ was reported by

Table 4 Relationship between fistula healing and mortality versus fistula classification, patient factors, and management plan

\begin{tabular}{lll}
\hline Independent variables & Fistula healing & Mortality \\
\hline Etiologic classification & $0.36 \mathrm{I}^{\mathrm{a}}$ & $0.15 \mathrm{I}$ \\
Anatomic & $0.125^{\mathrm{a}}$ & 0.406 \\
Physiologic & $0.67^{\mathrm{a}}$ & $0.017^{*}$ \\
Patient BMI category & $0.05^{\mathrm{a}}$ & $0.017^{*}$ \\
Nutrition support regimen & $0.149^{\mathrm{a}}$ & 0.48 \\
Glutamine & $0.429^{\mathrm{a}}$ & 0.303 \\
Days nil per mouth & $0.123^{\mathrm{b}}$ & 0.503 \\
Serum albumin at admission & $0.004^{*, \mathrm{~b}}$ & 0.274 \\
BMI at admission & $0.003^{*, \mathrm{~b}}$ & $0.00 \mathrm{I}^{*}$ \\
Age & $0.827^{\mathrm{b}}$ & 0.375 \\
\hline
\end{tabular}

Notes: asing Fisher's exact test; busing independent $t$-test; *significant at $P<0.05$. Abbreviation: BMI, body mass index. 
Gupta et al, ${ }^{16} 67 \%$ was reported by Harriman et al, ${ }^{17}$ and $53.3 \%$ was reported by Nursal Tark et al. ${ }^{18}$ This difference in reported rates is likely related to the experience and skill of the surgeon or the patient's condition. ${ }^{14}$

The mortality rate due to fistula complications was $14 \%$, and included sepsis, electrolyte disturbance, dehydration, and malnutrition. This is consistent with a report by Martinez et al, ${ }^{19}$ who found that these complications had a significant relationship with mortality. Gupta et $\mathrm{al}^{16}$ also reported a rate of $14 \%$, whereas a rate of $24.4 \%$ was reported by Nursal Tarık et al. ${ }^{18}$

Malnutrition was significantly related to mortality, as evidenced by the significant association of body mass index with mortality, even though it was not significantly associated with serum albumin level. Mawdsley et $\mathrm{al}^{20}$ found a significant difference in serum albumin levels between surviving and nonsurviving groups $(P=0.01)$. A large sample size could explain this significant relationship; however, their study did not investigate body mass index and its relationship with mortality.

We found no significant relationship between patient age and healing or mortality rates. This finding is not consistent with those of other studies; ${ }^{20}$ in clinical practice, mortality rate is generally affected by age and nutritional status. ${ }^{21}$

\section{Nutritional management and clinical outcome}

The cases were managed conservatively, as recommended by the published studies on management of fistula, ,7,10,22 with the exception of one case that was treated surgically. Conservative treatment was used to build up nutritional status, stabilize the patient before surgery, improve the surgical outcome, and decrease the risk of postoperative complications. ${ }^{11}$ A subjective global assessment was available for nine cases; seven were malnourished, indicating that this assessment was performed only for such cases. Due to the limited data on nutritional status in the patient files, assessment was based on body mass index and serum albumin level at admission or fistula recognition and the last albumin level before discharge. The significant relationship between serum albumin and spontaneous healing was in accordance with other similar studies. Nursal Tarık et $\mathrm{al}^{18}$ found a significant relationship between serum albumin and fistula healing $(P=0.014)$. Patients with healed fistula had higher serum albumin levels than those with non-healed fistulae. Harriman et al found a significant relationship between fistula healing and serum albumin levels, and fistula healing and prealbumin levels $\left(P=0.018\right.$ and $P=0.00$, respectively). ${ }^{17}$
Caloric and protein requirements have been shown to be affected by patient status, nutritional status, feeding tolerance, fistula output, and presence of complications such as refeeding syndrome and sepsis. ${ }^{23}$ Individualizing the nutritional management plan in terms of caloric and protein requirements and feeding route has been recommended in several studies. ${ }^{6,11,24}$

\section{Relationship between glutamine, fistula healing, and mortality}

Intravenous glutamine was administered to $41 \%$ of the patients. At our study center, glutamine is commonly given to patients with or at high risk of sepsis, including those with enterocutaneous fistula. However, administration of glutamine did not significantly improve the clinical outcome. Similar studies assessing the effects of glutamine or an immune-enhancing diet on the clinical outcome in patients with fistula were not found.

\section{Conclusion}

Nutritional status has a significant impact on both healing and clinical outcome of fistula. Building up nutritional status in patients with fistula is very important in conservative management and in preparing patients for surgical repair.

\section{Disclosure}

The authors report no conflicts of interest in this work.

\section{References}

1. Draus JM, Huss SA, Harty NJ, Cheadle WG, Larson GM. Enterocutaneous fistula: are treatments improving? Surgery. 2006; 140(4):570-578.

2. Dudrick S, Panait L. Metabolic consequences of patients with gastrointestinal fistulas. Eur J Trauma Emerg Surg. 2011;37(3):215-225.

3. Evenson AR, Fischer JE. Current management of enterocutaneous fistula. J Gastrointest Surg. 2006;10(3):455-464.

4. Taggarshe D, Bakston D, Jacobs M, McKendrick A, Mittal VK. Management of enterocutaneous fistulae: a 10 years experience. World $J$ Gastrointest Surg. 2010;2(7):242-246.

5. Pfeifer J, Tomasch G, Uranues S. The surgical anatomy and etiology of gastrointestinal fistulas. Eur J Trauma Emerg Surg. 2011;37(3): 209-213.

6. Schecter WP, Hirshberg A, Chang DS, et al. Enteric fistulas: principles of management. J Am Coll Surg. 2009;209(4):484-491.

7. Polk TM, Schwab CW. Metabolic and nutritional support of the enterocutaneous fistula patient: a three-phase approach. World J Surg. 2012;36(3):524-533.

8. Visschers RG, Damink SWO, Winkens B, Soeters PB, van Gemert WG. Treatment strategies in 135 consecutive patients with enterocutaneous fistulas. World J Surg. 2008;32(3):445-453.

9. Tong WM, Hope W, Overby DW, Hultman CS. Comparison of outcome after mesh-only repair, laparoscopic component separation, and open component separation. Ann Plast Surg. 2011;66(5):551-556.

10. Whelan J, Ivatury R. Enterocutaneous fistulas: an overview. Eur $J$ Trauma Emerg Surg. 2011;37(3):251-258. 
11. Yanar F, Yanar H. Nutritional support in patients with gastrointestinal fistula. Eur J Trauma Emerg Surg. 2011;37(3):227-231.

12. Shenkin A. Serum prealbumin: is it a marker of nutritional status or of risk of malnutrition? Clin Chem. 2006;52(12):2177-2179.

13. McNaughton V. Summary of best practice recommendations for management of enterocutaneous fistulae from the Canadian Association for Enterostomal Therapy ECF Best Practice Recommendations Panel. J Wound Ostomy Continence Nurs. 2010;37(2):173-184.

14. Lloyd D, Gabe S, Windsor A. Nutrition and management of enterocutaneous fistula. Br J Surg. 2006;93(9):1045-1055.

15. Khan L, Ahmed J, Khan S, MacFie J. Refeeding syndrome: a literature review. Gastroenterol Res Pract. 2010;2011:410971.

16. Gupta M, Sonar P, Kakodkar R. Small bowel enterocutaneous fistulae: the merits of early surgery. Indian J Surg. 2008;70(6):303-307.

17. Harriman S, Rodych N, Hayes P, Moser MAJ. The C-reactive proteinto-prealbumin ratio predicts fistula closure. Am J Surg. 2011;202(2): $175-178$.

18. Nursal Tarık Z, Ataç B, Hasan A, Ömer A. Factors affecting healing of enterocutaneous fistulas. Turk J Gastroenterol. 2000;11(3):222-226.
19. Martinez JL, Luque-de-León E, Ballinas-Oseguera G, Mendez JD, Juárez-Oropeza MA, Román-Ramos R. Factors predictive of recurrence and mortality after surgical repair of enterocutaneous fistula. J Gastrointest Surg. 2012;16(1):156-163.

20. Mawdsley J, Hollington P, Bassett P, Windsor A, Forbes A, Gabe S. An analysis of predictive factors for healing and mortality in patients with enterocutaneous fistulas. Aliment Pharmacol Ther. 2008;28(9): 1111-1121.

21. Dempsey D, Mullen J, Buzby G. The link between nutritional status and clinical outcome: can nutritional intervention modify it? Am J Clin Nutr. 1988;47(2):352-356.

22. Schecter WP. Management of enterocutaneous fistulas. Surg Clin North Am. 2011;91(3):481-491.

23. Tong CY, Lim LL, Brody RA. High output enterocutaneous fistula: a literature review and a case study. Asia Pac J Clin Nutr. 2012;21(3):464-469.

24. Yuan Y, Ren J, Gu G, Chen J, Li J. Early enteral nutrition improves outcomes of open abdomen in gastrointestinal fistula patients complicated with severe sepsis. Nutr Clin Pract. 2011;26(6): 688-694.
Journal of Multidisciplinary Healthcare

\section{Publish your work in this journal}

The Journal of Multidisciplinary Healthcare is an international, peerreviewed open-access journal that aims to represent and publish research in healthcare areas delivered by practitioners of different disciplines. This includes studies and reviews conducted by multidisciplinary teams as well as research which evaluates the results or conduct of such teams or

\section{Dovepress}

healthcare processes in general. The journal covers a wide range of areas and welcomes submission from practitioners at all levels, from all over the world. The manuscript management system is completely online and includes a very quick and fair peer-review system. Visit http://www.dovepress.com/testimonials.php to read real quotes from published authors. 